\title{
Commentary
}

\section{The Changing Face of Orthopaedic Education: Searching for the New Reality After COVID-19}

\author{
Kevin D. Plancher, M.D., M.P.H., Jaya Prasad Shanmugam, M.D., and \\ Stephanie C. Petterson, M.P.T., Ph.D.
}

\begin{abstract}
The COVID-19 pandemic has had immediate impact on the practice of medicine and on orthopaedic education. As the practice of social distancing has been put into place to help slow the spread of disease as well as to conserve medical supplies and equipment, elective surgery has come to a grinding halt. This dramatic change has forced our leaders to evaluate critically the delivery of education and skills training for our residents, fellows and all orthopaedic surgeons. We must continue to develop technologies, such as virtual meeting platforms, distance learning, simulation-based training, virtual reality and augmented reality to open up the new world of orthopaedic education.
\end{abstract}

\section{Introduction}

C OVID-19 has upended medicine and education, dramatically impacting how we learn and train our future surgeons. The American College of Surgeons, the Centers for Medicare and Medicaid Services and the United States Surgeon General have recommended delay of all elective and nonessential medical and surgical procedures so as to minimize the spread of disease and to conserve medical supplies and personal protective equipment and to avoid crisis levels for sick patients. These recommendations have had an immediate downstream effect on all orthopaedic residents' and fellows' education. New guidelines from the American Board of Medical Specialties and Accreditation Council for Graduate Medical Education have emerged and continue to evolve concerning how to achieve milestones and modify training log requirements while still being able to satisfy all graduation competencies. The

From the Department of Orthopaedics, Albert Einstein College of Medicine, Bronx, New York, U.S.A. (K.D.P.); Plancher Orthopedics and Sports Medicine, New York, New York, U.S.A. (J.P.S.); Orthopaedic Foundation, Stamford, Connecticut, U.S.A. (S.C.P.).

The authors report no conflicts of interest in the authorship and publication of this article. Full ICMJE author disclosure forms are available for this article online, as supplementary material.

Address correspondence to Kevin D. Plancher, M.D., M.P.H., 1160 Park Avenue, New York, New York 10128, U.S.A. E-mail: kplancher@ plancherortho.com

(C) 2020 THE AUTHORS. Published by Elsevier Inc. on behalf of the Arthroscopy Association of North America. This is an open access article under the CC BY-NC-ND license (http://creativecommons.org/licenses/by-nc-nd/4.0/).

2666-061X/20614

https://doi.org/10.1016/j.asmr.2020.04.007 majority of our annual and biennial meetings for our societies have been postponed or cancelled; some organizations are searching for answers to fill the need of keeping us current through virtual meetings, consisting of prerecorded talks to generate a web-based educational library. Surgical skills training and workshops are all on hold. The changing landscape of education has abruptly forced us to evaluate critically the current modes of education delivery.

COVID-19 has forced us to adopt, integrate and use technology rapidly to help us survive during these challenging times. We must think ahead and develop strategies for the integration of technology to minimize interruptions for residency and fellowship training programs and orthopaedic education in general. How will COVID-19 change the landscape of teaching and learning now and in the future? The following is a discussion of rapidly emerging education-delivery methods and the use of technology platforms-some that exist, some that must be developed further. These platforms may or may not be the new reality we must accept as we search to create the New World of Orthopaedic Education.

\section{Virtual Meetings}

Web-based meetings ${ }^{1}$ have almost become the norm for both start-up ventures and multinational companies. The technology of virtual meeting platforms has allowed businesses to overcome the burden of inperson meetings by decreasing costs of travel and time away from the office or, in some instances, when businesses are completely remote operations. ${ }^{2}$ Some common platforms for online meetings include Skype, 
Google Voice, WebEx, and Zoom audiovisual conferencing. The ease of sharing documents, photos and videos helps to facilitate meetings in ways that are no different from face-to-face events. Newer platforms are also being investigated to incorporate artificial intelligence to record pre- and post-meeting tasks. ${ }^{3}$

Attendance at daily or weekly educational activities or even multiple conferences in a calendar year is almost impossible for an orthopaedic surgeon under normal circumstances. Residents and fellows have variable schedules, often making attendance at grand rounds and journal clubs difficult for everyone to share. Virtual attendance using web-based services may be helpful to circumvent these issues.

Virtual-meeting technologies afford the possibility of educating surgeons around the world in the comfort and safety of their own homes. However, the question that must be raised is "How we can integrate these technologies into national and international meetings on a much larger scale?" If virtual meetings become the standard, can they offer the same benefits of in-person meetings, such as networking over a coffee, dynamic interactions on the podium, case-based panels with questions and answers? Will there be a loss of passion in these live question-and-answer sessions due to broadcasting delay? Some presenters might answer questions selectively, which may frustrate participants. Watching live surgery is exciting, but does watching in isolation without meeting other faculty members stifle important questions and fail to allow the subtleties of a technique to be brought to light?

Attending in-person conferences and trainings allows participants to walk away from personal and job demands and submerge themselves in rigorous training and education. Will this same sense of submersion happen with virtual conferences or prerecorded education events? Will the responsibility to report to work assumed by their supervisors take over? Will there be environmental distractions, such as dogs barking in the background, food being served to you by a family member, or someone speaking next to you at home while you are trying to listen on the computer? Will this lead to a loss of focus and retention of the educational materials? Will technological malfunctions, such as microphone feedback and delay in broadcasting, take away from the educational experience? These are questions to which we don't know the answers at the present time.

We have been taught that medicine is an art and a science. Medicine is a field dependent on human interaction. As a profession, we must critically evaluate the value of the face-to-face interaction and whether virtual meetings can serve as a substitute, particularly in a field that is dependent on human interaction and technical skills. Additionally, we must ask ourselves whether these technology platforms afford the same networking opportunities as in-person events. Will the human touch that can be so powerful during the healing process be lost?

\section{E-learning}

Distance learning has become part of the curriculum in many universities. Many orthopaedic societies have also already added educational materials to their websites. ${ }^{4}$ This type of learning uses electronic technologies to learn outside of a traditional classroom. Presentations can be prerecorded or presented live, allowing participants to learn at their own pace and can even provide the opportunity to go back and review what they have already learned. Some common programs include Blackboard, Moodle, Vista, and Angle. Many of these platforms have interactive features, such as chat and messaging, where listeners can actively engage with the presenters-no different from traditional question-andanswer periods. ${ }^{1}$ Webinars and podcasts can be added to this list of opportunities for participants. Attendance can be registered and monitored through these platforms to ensure accountability and provide continuing medical education credits.

Like virtual meeting platforms, e-learning circumvents geographic and scheduling constraints, avoiding costs associated with travel, food and lodging. Each institution can create its own curricula, and the residents and fellows can enroll and learn on their own time and at their own pace. It also allows for consistency among programs, providing the ability to learn from national and international experts rather than relying on the strengths of the faculty on staff.

This great opportunity exists, but we again must ask Does removing education from the classroom or clinic/ hospital setting fail to teach the art of human interaction and personal connection? Does e-learning afford the young resident the ability to understand the social determinants of the patient? Will the future of our workforce be able to recognize through e-learning that the patient they have just given a prescription to will never fill that prescription because of a transportation or a financial issue? Does that resident realize that that person can't even afford a new pair of shoes? Technology is a powerful tool that will likely emerge as an enhancement of educational experiences, but it should not serve as the sole replacement.

\section{Simulation-Based Training}

The breadth of orthopaedics and the specializations of physicians and surgeons have increased over the past few decades. Although this has led to improvements in patient care, the spectrum of surgeries, the diversity of pathologies and the technologic advances in each specialty area have made it extremely difficult for a resident or a fellow to master all the operative techniques in a limited period of time. Further, legal 
accountability for medical services and patient-safety monitoring has placed increased pressure on operational performance and outcomes. The restrictions imposed by social distancing and the availability and cost of cadavers for training also pose difficulties. Disruptive events such as COVID-19 disturb the typical mentor-mentee relationship and the traditional teaching that occurs in the operating room as well as in the clinic. Limited face-to-face interactions with mentors as well as patients have upended our traditional teaching models and clinical learning opportunities.

Simulation-based surgery is a rapidly evolving field. Trainees can practice a multitude of surgical procedures on one platform in a risk-free setting. ${ }^{5}$ This technology can boost surgeons' confidence and reduce the steepness of their learning curves, especially with technically demanding arthroscopic or open procedures. Simulation surgeries should be evaluated by experts and their effectiveness quantified before their institution in a training program. Institutions should have a method of recording trainees' performances and track their progress in the long term. Although still a newer technology, simulation-based surgery has the potential to influence greatly surgeons' training and efficiency. Although attractive, simulation training is not without its disadvantages and barriers. Simulation machines are very costly and often take up a significant amount of space that many hospitals and programs do not have, and they allow for only a few specific surgical procedures to be performed.

Further research is needed for better understanding of the transfer and retention of skills attained in a simulation-based surgical-skills training to live surgical cases. $^{6,7}$ Additionally, does simulation-based training compromise nontechnical skills essential to patient care? There is likely to be a balance between the simulation-based cadaveric skills training and live surgical cases. This balance has yet to be determined.

\section{Virtual and Augmented Reality}

Virtual reality (VR) uses computer technology to create a realistic, 3-dimensional, simulated environment as well as to provide visual feedback from body movements. ${ }^{8}$ First emerging in the gaming and entertainment industries, virtual reality has now made its way into surgical-skills training as a tool to provide repeated exposure to a skill or procedure.

VR can provide either augmented or mixed reality. ${ }^{9}$ Augmented reality may enhance the training experience by overlaying a real clinical environment onto the experience rather than performing in a virtual world. Some examples of commercially available VR, augmented-reality, and mixed-reality headsets include Occulus Rift, HTC Vive, Microsoft Hololens and, perhaps the more widely known mobile application, Pokemon go, that utilizes this reality.
VR helps the surgeon with constructive learning, improves problem-solving skills and provides a safe environment for making mistakes. In the future, virtual meeting platforms can be combined with VR technology to provide participants with more of a real-time feel than watching a screen. Trainees and practicing surgeons should be able to watch live surgeries with VR and interact with the surgical team.

VR overcomes some of the challenges of simulatorbased training previously mentioned, making this technology more portable and more easily accessible. Several of the existing arthroplasty companies have already adapted VR into orthopaedic surgery training, and it is on trial. We await the results to better understand how to integrate VR into traditional teaching models.

\section{Mobile Devices}

Mobile-based apps are also a great source for education. ${ }^{1}$ One of the primary advantages of a mobile device is quick access to educational materials, such as journals, e-books and surgery videos. Mobile apps are also already widely in use to aid surgeons in navigating conferences and in tailoring events to their specific educational needs. Industry has also adopted these technologies, allowing surgeons virtual tours of their exhibit booths and helping surgeons to familiarize themselves with a myriad of surgical equipment and techniques.

Surgical-planning apps are a great tool for surgeons to minimize errors and confusion in the operating room. Surgeons can share the plan and instrument details with the entire surgical team. Using the mobile device with social media has become an integral part of daily medical life. Patient privacy should always be kept in mind while using blogs and social media. Social media may someday help young practitioners to solve problems of difficult cases as well as create long-term, meaningful contacts with experienced surgeons.

\section{Glimpse From the Human Side: Annual Meetings}

As we continue to watch meetings from around the world being cancelled or rescheduled, we must wonder what our annual meetings might look like in the future. The annual meeting is one of the pillars of our societies. It provides societies the opportunity to show yearly progress, to recognize the women and men who are leaders in research and clinical accomplishments, to reconnect with industry and with each other. The mission of the Arthroscopy Association of North America (AANA) and similar educational organizations is to advance the art and science of arthroscopy and minimally invasive surgery through education, skills assessment and advocacy. Can all this be done on a computer screen?

Before we know what we need, we must consider the current situation. The recommendations for maintaining 
safe meetings might range from taking participants' temperatures on site, answering questionnaires and checking vaccination documents to social distancing, wearing masks and gloves and possibly much more. When or if the immediate threat is gone, many will agree it might be time to assemble again, but with caution. Will convention centers have temperature scanners like airport metal detectors for everyone or will we be required to have health and vaccination records to board a plane? It is interesting to note that animals such as cows and horses, when crossing state lines, are required to have health certificates. If testing can be successful, with low false-negative rates, might it be required at all meetings of more than 5 individuals?

One of the special parts of our annual meetings is the opportunity to interact and network. Social distancing is not part of our meetings. Can we really give up the person-to-person meetings, where we get to talk to manufacturers who develop new equipment, talk to the old guard and bring the new guard along? Taking away the casual meeting over a cup of coffee seems like a deadly blow; but will it be necessary to be safe? Might we never have these simple things ever again?

We look toward to the future for new technology, which may help the online annual meeting look more appealing. Virtual reality, with the use of holograms, is one way surgical demonstrations can move forward, as already discussed. Imagine placing your personal VR mask on your head and literally walking down the hall to register when you run into the President of AANA. You can then go to the exhibit area and talk to vendors, no different from the way it used to be. This convenience can all be done from the comfort of your own home. The future might have the solutions for a contact-free annual meeting using virtual 3dimensional environments, but, again, we must ask-at what cost?

The unsettling question is how or whether our society wants to gather its members. Medicine and the care of patients have always been based on human interaction. The subtleties of a smile, the interpretation of anxiety, all this may be lost if we can't meet face-to-face. One must hope that we will figure out a way to meet this goal of gathering once again and improve on the process of teaching each other so that our patients benefit from our profession of selfless service.

\section{Summary}

The future of orthopaedic training is rapidly evolving. Technology is and will be an integral part of this evolution. New innovations are being made every day. With increasing pressure on surgeons to deliver high-quality patient care, it is important to find novel avenues to educate and train surgeons nationwide while maintaining efficient and safe patient care. It is the responsibility of surgeons to keep themselves updated with new developments and technology. National and international orthopaedic societies and teaching institutions worldwide should consider using the above-mentioned methodologies and more to enhance education and training.

In the end, some of us may remember 2019 as the last real meeting. Some may say 2021 will be the new era with, perhaps, a hybrid meeting. Now we have the opportunity to decide how and what we must change in this new era. Let's make sure that however we move forward, we do it with safety in mind for all of us and keep the traditions and mission of our society alive.

\section{References}

1. Moran J, Briscoe G, Peglow S. Current technology in advancing medical education: Perspectives for learning and providing care. Academ Psychiat 2018;42(6):796-799. doi: 10.1007/s40596-018-0946-y.

2. Fraser H, Soanes K, Jones SA, Jones CS, Malishev M. The value of virtual conferencing for ecology and conservation. Conserv Biol 2017;31:540-546. doi:10.1111/cobi.12837.

3. Nanos AG, James AE. A virtual meeting system for the new age. Proceedings: 2013 IEEE 10th International Conference on e-Business Engineering, 2013. 98-105. https://doi.org/ 10.1109/ICEBE.2013.15.

4. Hunt TJ, Brand JC, Rossi MJ, Lubowitz JH. My kind of town (Chicago Is): Content collections optimize learning related to the 2018 AANA annual meeting. Arthroscopy 2018;34:1001-1004. doi:10.1016/j.arthro.2018.02.018.

5. Stirling ERB, Lewis TL, Ferran NA. Surgical skills simulation in trauma and orthopaedic training. J Orthopaed Surg Res 2014;9:126. doi:10.1186/s13018-014-0126-z.

6. van der Heijden LLM, Reijman M, van der Steen MCM, Janssen RPA, Tuijthof GJM. Validation of Simendo Knee Arthroscopy Virtual Reality Simulator. Arthroscopy 2019;35: 2385-2390.

7. Frank RM, Wang KC, Davey A, et al. Utility of modern arthroscopic simulator training models: A meta-analysis and updated systematic review. Arthroscopy 2018;34: 1650-1677.

8. Aarseth E. Virtual worlds, real knowledge: Towards a hermeneutics of virtuality. Eur Rev 2001;9:227-232. doi:10. 1017/S1062798701000205.

9. $\mathrm{Hu} \mathrm{Au}$ E, Lee JJ. Virtual reality in education: A tool for learning in the experience age. Int J Innov Educ 2017;4:215. doi:10.1504/ijiie.2017.10012691. 